\title{
Motivation, Beliefs, and Attitudes Towards Mathematics and Its Teaching
}

\author{
Birgit Pepin and Ji-Won Son
}

\section{Report}

Affect has been a topic of interest in mathematics education research for more than 30 years. More recently, and as emphasized in the last ICME 11 report, beliefs has turned from a 'hidden' to a more 'visible' variable. Today we know that affective variables can be regarded as explicit factors which influence mathematics learning outcomes as well as instructional practice. The different research perspectives used in studies of affect include psychological, social, philosophical, and linguistic. Those various views were represented in the ICME 12 research presentations. It also became clear during the conference, and this was expected, that the construct of 'affect' encompasses related constructs such as 'motivation', 'beliefs', 'values' and 'attitudes', to name but a few. We invited, and received, presentation proposals on all areas of affect in mathematics learning and teaching.

The organizing committee organized the accepted papers and posters for TSG 27 in the following ways:

Organizers Co-chairs: Birgit Pepin (Norway), Ji-Won Son (USA); Team Members: Bettina Roesken (Germany), Inés $\mathrm{M}^{\mathrm{a}}$ Gómez-Chacón (Spain), Nayoung Kwon (Korea); Liaison IPC Member: Bill Barton.

\author{
B. Pepin ( $\square)$ \\ Soer-Troendelag University College, Trondheim, Norway \\ e-mail: birgit.pepin@hist.no \\ J.-W. Son \\ University of Tennessee, Knoxville, USA \\ e-mail: sonjwon@utk.edu \\ (C) The Author(s) 2015
}


- One 'elicited' Roundtable on 'Methodological issues in Affect Research';

- Six groups of short paper presentations and discussions (15 min);

- Three long paper presentations (30 min);

- Posters in the general poster session.

We had a large number of proposals and rigorously reviewed them, each proposal being evaluated by three reviewers (members of the TG27 team) according to a common set of criteria (agreed review scheme). At the advice of the ICME organizing committee we accepted most, only rejecting about six proposals, and arranged the accepted proposals in sessions. As we had four 90-min sessions (July 10, 11, 13, and 14) available, we decided to run parallel sessions, allocating 20-30 min for long and 10-15 min for short presentations. Each session was chaired by one of the co-chairing team members (unfortunately Inés $\mathrm{M}^{\mathrm{a}}$ GómezChacón could not attend ICME 2012). Posters were allocated to the poster session, which was common for all TSGs. One of the highlights of the TSG 27's sessions was the 'elicited' Roundtable on methodological issues, which had a 60-min time allocation.

The following will provide a 'taste' of the presentations and issues discussed.

On the 10th July the co-chairs opened up the first of four one and half hour sessions. Subsequently, Jill Cochran presented her research asking questions concerning values and ideals in mathematics education. She argued that teachers, policy makers, curriculum developers, and other professionals often held ideals that were in opposition to each other, and that this created conflicts of interest, in particular for classroom teachers. The following two sessions ran parallel, and each parallel session included three short presentations on the following topic areas: 'Students' views of mathematics'; and 'Mathematics teacher knowledge and efficacy'. Each series of presentations was followed by a discussion of the presentations.

On the 11th July the (elicited) Methodology Roundtable and one short presentation were scheduled. The panel members of the Roundtable were all well-known researchers in the field of affect in mathematics education: Markku Hannula; Gilah Leder; Ilana Horn; and Guenter Toerner. Each outlined their insights concerning methodological issues, and Markku Hannula presented a theoretical framework for the inclusion of the different 'lenses'. Then questions about the framework and relevant issues were discussed.

The 12th July session started with a (long) presentation by Mac an Bhairs Ciaran and colleagues on the 'effect of fear on engagement with mathematics'. They reported on a comparative study of first year undergraduate mathematics students: one group had failed their first year examinations; the second had successfully completed the first year. It was argued that whilst both groups named 'fear' as a factor for engagement (or not) with mathematics, for one group it emerged as a positive motivation, in the sense that it formed part of their coping mechanisms when dealing with the various obstacles that they encountered. The subsequent parallel sessions included six (short) presentations, under the headings of 'Motivation and conditions 
for pupil learning' and 'Teacher beliefs concerning curriculum and tracking'. Again, each series of presentations was followed by a discussion of the presentations.

The last TGS 27 session had a similar structure, albeit more time was allocated for discussion of the whole TGS, insights gained and implications for future research (as this was the last session of the TSG). In an opening (long) presentation Birgit Pepin reported on a study of 'Affective systems of Norwegian mathematics students/teachers in relation to 'unusual' problem solving'. She argued that results from the three different groups (each at different stages of their educational and professional development) showed that positive engagement structures were linked to working together in a group and previous (positive) experiences, whereas 'giving up' was connected to 'working alone' and the 'unusual' problem-solving situation. The subsequent two parallel sessions (including altogether four (short) presentations) were in the two themes of 'Teacher beliefs and practices' and 'Teachers' views on mathematical tasks'.

In a final discussion the following issues were raised:

1. Five minutes for (short) presentations is not sufficient. Hence, either a different mode of running the TGS should be found, or (fewer) presenters should be given more time, also for discussion. This has implications for acceptance of future proposals: this ICME the TGS 27 had a very large number of proposals, and approximately half were accepted as short or long presentations (19), and approximately half accepted as posters (with a small number of rejections). Hence, questions arise: should the reviewing process (TGS 27 had three reviewers and developed its own evaluation schedule) be more rigorous, and more papers be rejected? Or should the TSG be 'inclusive' and find another mode of running the group?

2. The question of 'publication' was raised: presentations were 'published' in the ICME 12 pre-proceedings, but how does this count/is acknowledged in terms of publications?

3. It was suggested to be more selective about the accepted papers and support, and perhaps elicit, more 'novelty' topic areas: e.g. affect and mathematical thinking (including suitable theoretical frameworks and measurement instruments/ methodological tools for this field of research); affect as a dynamic system (including affective systems and 'collectives' in social contexts); intervention studies/design-based research on 'affect and cognition'.

4. TGS 27 was provided with two rooms close to each other (and this was beneficial for participants to be able to attend sessions). However, it was difficult for the group to 'merge' as a whole, as many discussions took place in separate sessions, and some participants wanted to share their ideas in a whole group discussion.

5. Overall, it was emphasized that this ICME's TGS on affect went well (as did previous groups) and that this group is now an established and well-recognized part of ICME. 


\title{
List of Groups, Presentations and Presenters of Long and Short Presentations
}

\author{
Tuesday, 10th July
}

Jill Cochran, Does a balanced philosophy in mathematics education exist?

Student views of mathematics:

- Mario Sanchez Aguilar, Alejandro Rosas and Juan Gabriel Molina Zavaleta, Mexican students' images of mathematicians

- Sally Hobden, After graduation? The beliefs of alumni bachelor of education students reading mathematics and the formation of mathematical knowledge

- Veronica Vargas Alejo, Cesar Cristobal Escalante and Jamal Hussain, Beliefs and attitudes toward mathematics at university Level, development of mathematical knowledge

Teacher knowledge and efficacy

- Janne Fauskanger, Teachers' epistemic beliefs about HCK

- Giang-Nguyen Nguyen, Diagnosing student motivation to learn mathematics: A form of teacher knowledge

- Ayse Sarac and Fatma Aslan-Tutak, The relation of teacher efficacy to students' trigonometry achievement

Wednesday, 11th July

Methodological issues

Dohyoung Ryang, The viability of the mathematics teaching efficacy beliefs instrument for Korean secondary pre-service teachers

Roundtable (Co-chairs: Bettina Roesken and Birgit Pepin; Panel members: Markku Hannula, Gilah Leder, Ilana Horn and Guenter Toerner)

Methodological issues in Affect Research: distinguishing between 'state' and 'trait' in mathematics education research.

Friday, 13th July

Mac an Bhaird Ciaran, The effect of fear on engagement with mathematics Motivation and conditions for pupil learning

- Chonghee Lee, Sun Hee Kim, Bumi Kim, Soojin Kim and Kiyeon Kim,

- Denival Biotto Filho and Ole Skovsmose, Researching foregrounds: About motives and conditions for learning

- Nelia Amado ${ }^{1}$ and Silvia Reis, A young student's emotions when solving a mathematical challenge

- Suela Kacerja, "Cultural products are girls' things!” Interests Albanian students retain for real-life situations that can be used in mathematics

Teacher beliefs concerning curriculum and tracking

- Qian Chen, Teachers' beliefs and mathematics curriculum reform: A comparative study of Hong Kong and Chongging 
- Benjamin Hedrick and Erin Baldinger, Beliefs about tracking: Comparing American and Finnish prospective teachers

Saturday, 14th July

Birgit Pepin: "Exploring affective systems of Norwegian mathematics student/ teachers in relation to 'unusual' problem solving"

Teacher beliefs and practices

- Dionne Cross and Ji Hong, "I'm not sitting here doing worksheets all day!": A longitudinal case study exploring perceived discrepancies between teachers' beliefs and practices

- Ralf Erens ${ }^{1}$ and Andreas Eichler ${ }^{1}$, Teachers' curricula beliefs referring to calculus

Teacher views on mathematics tasks

- Esther Levenson, Affective issues associated with multiple-solution tasks: Elementary school teachers speak out

- Anika Dreher and Sebastian Kuntze, Pre-service teachers'views on pictorial representations in tasks

Open Access This chapter is distributed under the terms of the Creative Commons Attribution Noncommercial License, which permits any noncommercial use, distribution, and reproduction in any medium, provided the original author(s) and source are credited. 